Pollution

\section{Out of Africa}

\section{B Brunekreef}

\section{Commentary on the paper by Venn et al (see page 376)}

M any studies from the west have implicated traffic pollution in respiratory disease, especially in children. Usually, these studies have been conducted in areas with high traffic densities such as inner cities, or areas near major highways. The daily number of vehicles passing on roads near residences or schools of study children have typically been in the tens of thousands, sometimes well over one hundred thousand. Air pollution studies conducted near such roads have shown relatively high concentrations of traffic related air pollutants, compared to sites away from the direct influence of busy roads. Typically, such contrasts were markedly larger for specific components such as $\mathrm{NO}_{2}$, soot, PAHs, and benzene than for particulate matter metrics of current regulatory interest, $\mathrm{PM}_{10}$ and $\mathrm{PM}_{2.5 \cdot{ }^{12}}$

In this issue, a study is presented from Jimma, Ethiopia. Jimma is a small town of some 100000 inhabitants, located far away from the main population centre in Ethiopia, Addis Ababa. ${ }^{3}$ It has no major industry, few inhabitants can afford cars, and one would expect air pollution levels from traffic to be exceedingly low. Yet this new study suggests that subjects living close to the small number of paved roads that Jimma has, experience more wheeze, the closer they live to these roads. However, median traffic density during the daytime was only 653 vehicles, with a range of only up to about 2500 vehicles per 12 daytime hours. This is some two orders of magnitude less than the traffic densities studied in the west, and it is puzzling that relatively similar findings were obtained.

So how likely is it that 600 vehicles per day produce enough air pollution to adversely affect the health of subjects living close to the road? The answer perhaps is in the age and maintenance of the vehicle fleet. We sometimes forget that in developed countries, cars have become incredibly cleaner in a period of decades. This is due to changes in engine design, to changes in fuel composition, and introduction of catalytic converters. Also, the introduction of mandatory inspection programmes for older vehicles, including emissions testing, has likely resulted in the timely removal of the dirtiest part of the vehicle fleet from our roads. Ironically, whereas some of these vehicles no doubt end up in our own scrap yards, others start a second, most likely even more polluting life in poor countries without the proper institutions or funds to do much of anything to reduce pollution. Not too many references can be found to quantitatively document what the results could be. A report from Tehran, $\operatorname{Iran}^{4}$ argues that the 2 million vehicles on the roads are so old that many are highly polluting. Surely, the $\mathrm{PM}_{10}$ concentrations reported for Tehran are in the hundreds of $\mu \mathrm{g} / \mathrm{m}^{3}$, much higher than anything found in similarly sized cities in the developed world with even larger vehicle fleets. But even in the developed world, despite all our efforts, so-called "super emitters" are still said to contribute significantly to air pollution concentrations, in the order of $50 \%$ of emissions being generated by just $10 \%$ of the vehicle fleet. ${ }^{56}$

So imagine what it would be like to have a vehicle fleet consisting largely or entirely of "super emitters". A picture tells a thousand words, and fig 1, kindly supplied by Dr Venn, illustrates the point forcefully. It seems at least con-

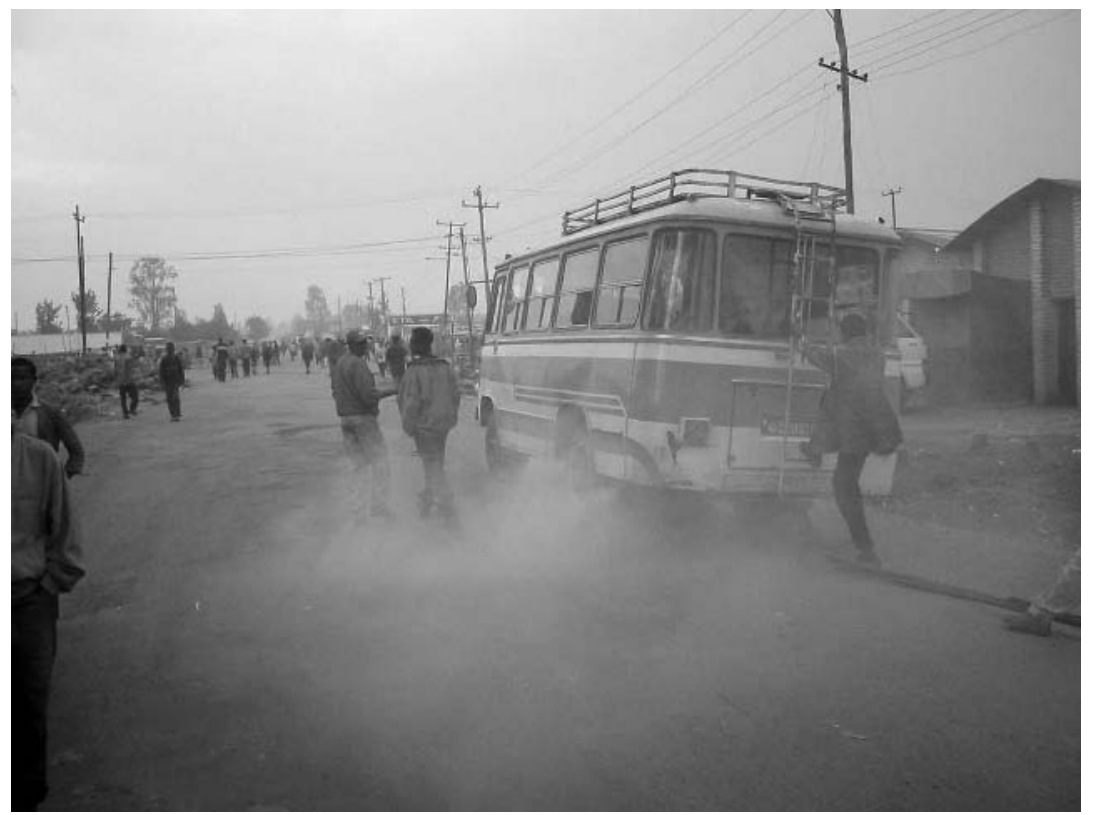

Figure 1 A traffic scene from Jimma, Ethiopia. ceivable that 600 vehicles in Jimma count for a lot more, in terms of pollutant emissions, than 600 vehicles in Nottingham. The fact that Jimma lies at $5500 \mathrm{ft}$ elevation adds to fuel consumption, and therefore to pollution as well.

Some others aspects were noticeable. The investigators made separate counts of diesel vehicles, but could not show that these were more specifically related to wheeze than total counts, as in our earlier work in the Netherlands. ${ }^{78}$ However, Dr Venn told me that the correlation between diesel and total vehicle counts was high (as is often the case), so that the study was not in a good position to actually make the separation. Another is that vehicle counts were made several years after the symptom questionnaire was administered. This could be a problem when important changes over time in paved road network and/or road usage would have occurred, but this does not seem to have happened (Dr Venn, personal communication).

Venn and colleagues' paper also shows that the prevalence of wheeze was not smaller in subjects living away from the roads than in the subgroup living within $150 \mathrm{~m}$, in which a distance-response relation was found. This shows, as one would expect in a multifactorial condition such as wheeze, that overall, other factors than traffic fumes are likely to be more important as determinants of symptom prevalence. Nevertheless, the study shows that at least in some part of the population, symptoms were caused, or exacerbated by traffic fumes. Welcome, Jimma residents, to the developed world ... 
Occup Environ Med 2005;62:351-352. doi: 10.1136/oem.2005.019927

Correspondence to: Prof. B Brunekreef, Institute for Risk Assessment Sciences, Utrecht University, PO Box 80176, 3508 TD Utrecht Netherlands; b.brunekreef@iras.uu.nl

Competing interests: none declared

\section{REFERENCES}

1 Fischer PH, Hoek G, van Reeuwijk H, et al. Trafficrelated differences in outdoor and indoor concentrations of particles and volatile organic compounds in Amsterdam. Atmosf Environ 2000;34:3713-22.

2 Harrison RM, Jones AM, Lawrence RG. Major component composition of $\mathrm{PM}_{10}$ and $\mathrm{PM}_{2.5}$ from roadside and urban background sites. Atmosf Environ 2004;38:4531-8.

3 Venn A, Yemaneberhan $\mathrm{H}$, Lewis $\mathrm{S}$, et al. Proximity of the home to roads and the risk of wheeze in an Ethiopian population. Occup Environ Med 2005;62:376-80.

4 Halek F, Kavouci A, Monehaie H. Role of motor vehicles and trend of airborne particulates in the great Theran area, Iran. Int J Environ Health Res 2004; 14:307-13.

5 Anilovich I, Hakkert AS. Survey of vehicle emissions in Israel related to vehicle age and

\begin{abstract}
periodic inspection. Sci Total Environ 1996; 190: 197-203.

6 Sjodin A, Andreasson K, Wallin M, et al. Identification of high-emitting catalyst cars on the road by means of remote sensing. Int J Vehicle Design 1997; 18:326-39.

7 Janssen NA, Brunekreef $B$, van Vliet $P$, et al. The relationship between air pollution from heavy traffic and allergic sensitization, bronchial hyperresponsiveness, and respiratory symptoms in Dutch schoolchildren. Environ Health Perspect 2003;111:1512-18.

8 van Vliet $\mathbf{P}$, Knape $M$, de Hartog J, et al. Motor vehicle exhaust and chronic respiratory symptoms in children living near freeways. Environ Res 1997;74:122-32.
\end{abstract}

\section{Mercury from dental amalgam: looking beyond the average}

\section{Barregard}

\section{Commentary on the paper by Dye et al (see page 368)}

M ercury $(\mathrm{Hg})$ is a toxic heavy metal occurring in several physical and chemical forms. Elemental mercury $\left(\mathrm{Hg}^{0}\right)$ emitted to the atmosphere is converted to soluble forms, deposited into soil and water, and methylated. Methylmercury (MeHg) bioaccumulates up the aquatic food chain and reaches the human diet. $^{12}$ Fish and dental amalgam are two major sources of human exposure to organic and inorganic $\mathrm{Hg}$, respectively.

Even when dental mercury amalgam (at present about $50 \%$ mercury by weight) was introduced more than 150 years ago there was concern about its toxicity. After several "amalgam wars", the safety of dental amalgam was established, however, and no uptake of mercury was supposed to occur from amalgam fillings. The debate was revived more than two decades ago in Europe, and then in North America. In the 1980s several studies confirmed that dental amalgam is a significant source of exposure to mercury in humans, mainly by inhalation of $\mathrm{Hg}^{0} .^{12}$ New assessments of exposure and risk were made by national bodies. ${ }^{3}{ }^{4}$ Usually the conclusions were that dental amalgam is a source of low level exposure to mercury, but there is no evidence of adverse health effects at these levels. In some countries strong anti-amalgam groups have formed, and policy has changed, aiming at decreasing or abolishing the use of dental amalgam.
The scientific discussion has focused on two questions: What is the dose? Could it cause symptoms and/or disease?

\section{HOW MUCH?}

In this issue, Dye and coworkers present recent data on urinary mercury $(\mathrm{U}-\mathrm{Hg}$ ) in a representative sample of about 1600 US women aged 16-49 years from the NHANES study of 1999-2000. ${ }^{5}$ This is an important piece of information on the exposure to inorganic mercury in the USA. The overall geometric mean (GM) was $0.71 \mu \mathrm{g} / \mathrm{g}$ creatinine $(\mu \mathrm{g} / \mathrm{gC})$ and the arithmetic mean (AM) was $1.1 \mu \mathrm{g} /$ gC. Since the distribution usually is approximately log normal, the GM is roughly the same as the median. The mean number of amalgam surfaces in posterior teeth was estimated to be 8.7, although the filling material was not registered. (One molar tooth has five is, representing the chewing area.) In women without dental amalgam, the $\mathrm{GM}$ was $0.31 \mu \mathrm{g} / \mathrm{gC}$, and it increased with the estimated number of amalgam surfaces.

These U-Hg levels are similar to those found in Central or Northern Europe; for example, medians of $0.2,0.3,0.6$, and $1.0 \mu \mathrm{g} / \mathrm{gC}$ in about 4800 Germans with $0,1-4,5-8$, and $>8$ teeth filled with amalgam, respectively. ${ }^{6}$ The levels along the Mediterranean coast are usually higher, $1-2 \mu \mathrm{g} / \mathrm{gC}$ in Italy and Portugal, owing to the impact of surfaces, one of which is occlusal-that demethylated MeHg from fish consumption, ${ }^{7}$ and the same is true for Japan.

For comparison, the TLV (threshold limit value) for occupational exposure to $\mathrm{Hg}^{0}$ is $25 \mu \mathrm{g} / \mathrm{m}^{3}$ in many countries, which will result in average U-Hg levels of about $30 \mu \mathrm{g} / \mathrm{gC}$ at long term exposure. $^{8}$ However, in modern industry, the typical $\mathrm{U}-\mathrm{Hg}$ is lower, and in dentists and dental nurses it is close to the background level in the general population. $^{910}$

Urinary mercury excretion of $1 \mu \mathrm{g} / \mathrm{gC}$ corresponds roughly to an uptake of 3$4 \mu \mathrm{g}$ inorganic $\mathrm{Hg} / \mathrm{day}$, assuming $1.5 \mathrm{~g}$ creatinine $/ 24 \mathrm{~h}$ and a faecal excretion of mercury similar to that in urine, or higher.

The paper by Dye et al confirms that dental amalgam is a major determinant for U-Hg. However, the bottom line ("main message") that 10 posterior amalgam surfaces would result in an increase in U-Hg of $1.8 \mu \mathrm{g} / \mathrm{gC}$ must be questioned. This figure was obtained simply by multiplying the regression coefficient in table $5(0.06)$ by 10 , and taking the antilog of 0.6 , which is 1.8 .

But if $\ln \mathrm{U}-\mathrm{Hg}$ increases with 0.6, then the untransformed $\mathrm{U}-\mathrm{Hg}$ will be multiplied by 1.8 , and the increase with 10 posterior surfaces will depend on the starting point. The intercept is important at low levels and the model chosen assumes a curvilinear (exponential) increase. It is not possible to state in general terms how much U-Hg will increase with 10 additional amalgam surfaces. When the background concentration (given by the authors for dentate women with no dental restorations) is $0.31 \mu \mathrm{g} / \mathrm{gC}, 10$ additional surfaces will result in an increase of the geometric mean by $0.25 \mu \mathrm{g} / \mathrm{gC}$. Similarly, if the $\mathrm{GM} \mathrm{U}-\mathrm{Hg}$ is $0.71 \mu \mathrm{g} / \mathrm{gC}$, as in the "average US woman" with nine surfaces, and 10 more surfaces are added, the model will predict an increase of $0.57 \mu \mathrm{g} / \mathrm{gC}$. The corresponding AM will be somewhat higher, but much lower than $1.8 \mu \mathrm{g} / \mathrm{gC}$. In fact, the study in US men referred to by the authors ${ }^{11}$ found 
an increase of $0.6 \mu \mathrm{g} / \mathrm{gC}$ per 10 surfaces, which is similar to my interpretation of the NHANES data.

However, the regression coefficient for a continuous variable can be transformed into a percent increase per surface. The study by Dye et al estimates an increase by about $6 \%$ per posterior amalgam surface. This is higher than previously reported. ${ }^{11}{ }^{12}$

\section{IS IT SAFE?}

Mild subclinical effects on the CNS may occur at occupational exposure levels with U-Hg of about $25 \mu \mathrm{g} / \mathrm{gC} .^{1}$ Another early effect commonly reported is that on the renal proximal tubules. Small molecular weight proteins and lysosomal enzymes are found in urine in increased amounts. Such effects have been reported at occupational exposure at $\mathrm{U}-\mathrm{Hg}$ as low as $10-20 \mu \mathrm{g} / \mathrm{gC} .^{13}$ Although some studies have suggested effects on the CNS at even lower occupational exposure in dentists, ${ }^{9}$ this has not been confirmed by others, ${ }^{10}$ and the debate about dentists is still ongoing. ${ }^{214}$ As Dye et al point out, long term follow up in children treated with dental amalgam or composites ("controls") is being performed in two controlled trials. These studies, the Children Amalgam Trial (CAT study) in Boston and Maine, and the Casa Pia study in Portugal, will hopefully shed more light on this issue with respect to low level exposure early in life.

Even if we consider the evidence of effects below $10 \mu \mathrm{g} / \mathrm{gC}$ too weak, does it imply that mercury from dental amalgam is always safe? Not necessarily, if we look beyond the average. Taking the overall SD for lnU-Hg given by Dye et al (0.96), an ideal log normal distribution predicts the 99 percentile to be $6.6 \mu \mathrm{g} / \mathrm{gC}$ and the 99.9 percentile $14 \mu \mathrm{g} / \mathrm{gC}$. This fits well with the right tail actually found $(6 \mu \mathrm{g} / \mathrm{gC}$ and $14 \mu \mathrm{g} / \mathrm{gC}$ even if three higher outliers were excluded (B Dye, personal communication). It implies that about one in 1000 US women of this age have a urinary $\mathrm{Hg}$ higher than in many settings with occupational mercury exposure, and similar to levels that result in discrete effects on the kidneys. In the study of US men the 99 percentile was about $7 \mu \mathrm{g} / \mathrm{gC}$ and the 99.9 percentile about $20 \mu \mathrm{g} / \mathrm{gC} .{ }^{11}$
Similar estimates for the Swedish general population were presented in this journal in the 1990s. ${ }^{15}$ Owing to a higher amalgam load (typically 30 surfaces) and higher U-Hg levels (geometric mean $2 \mu \mathrm{g} / \mathrm{gC}$ ) in Swedish subjects, the 99 percentiles and 99.9 percentiles were then estimated at 10 and $25 \mu \mathrm{g} / \mathrm{gC}$, respectively.

The variability of U-Hg is not caused only by the variability in number of amalgam surfaces. Cases with high U$\mathrm{Hg}$ levels may be found among heavy chewing gum users; for example, a median of $11 \mu \mathrm{g} / \mathrm{gC}$ (maximum $25 \mu \mathrm{g}$ / $\mathrm{gC})$ in 18 long term users of nicotine chewing gum. ${ }^{16}$ Urinary mercury as high as $50 \mu \mathrm{g} / \mathrm{gC}$ may be caused by dental amalgam. ${ }^{15}$ High levels were also reported in people eating large amounts of contaminated fish; for example, a median of $7 \mu \mathrm{g} / \mathrm{gC}$ (maximum $22 \mu \mathrm{g}$ / $\mathrm{gC})$ in 22 men with high consumption of tuna, ${ }^{17}$ or in those who use skin lightening creams or other mercury containing ointments.

If we accept that dental amalgam in rare cases, for example, at intense long term chewing, may result in high exposure with U-Hg levels of $10-50 \mu \mathrm{g} /$ $\mathrm{gC}$, we should accept that in those cases it could slightly affect the kidneys and the CNS.

In summary, the average mercury dose from amalgam fillings is in most cases below $5 \mu \mathrm{g}$ per day on average, ${ }^{1}$ but the issue of the right tail of the distribution is more important. A substantial number of persons have a mercury uptake from dental amalgam that is higher than should be accepted. Many of these cases are likely to be found among people with intense chewing gum use. Fortunately an increased $\mathrm{Hg}$ uptake can easily be shown in a urine sample.

\section{ACKNOWLEDGEMENTS}

I thank Dag Ellingsen and Gerd Sällsten for their comments on the draft manuscript.

Occup Environ Med 2005;62:352-353.

doi: 10.1136/oem.2004.018911

Correspondence to: Professor L Barregard, Department of Occupational and Environmental Medicine, Sahlgrenska University Hospital and Academy, PB 414, 405 30 Goteborg, Sweden; lars.barregard@amm. gu.se

Competing interests: none

\section{REFERENCES}

1 World Health Organisation. Concise International Chemical Assessment Document 50. Elemental mercury and inorganic mercury compounds: human health aspects. Genevo: WHO, 2003.

2 Clarkson TW. The three modern faces of mercury. Environ Health Perspect 2002;110(suppl I): 1 1-23.

3 US Public Health Service, Department of Health and Human Services. Dental amalgam: a scientific review and recommended Public Health Service strategy for research, education and regulation. Washington, DC, 1993

4 Richardson GM. Assessment of mercury exposure and risks from dental amalgam. Final report. Canada: Medical Devices Bureau, Environmental Health Directorate, Health, 1995.

5 Dye BA, Schober SE, Dillon CF, et al. Urinary mercury concentrations associated with denta restorations in adult women 16-49 years: United States, 1999-2000. Occup Environ Med 2005;62:368-75.

6 Becker K, Schulz C, Kaus S, et al. German Environmental Survey 1998 (GerES III): environmental pollutant in the urine of the German population. Int J Hyg Environ Health 2003;206: 15-24.

7 Barregard L. Exposure to mercury in the general population of Europe and the Arctic. In: Pirrone N, Mahaffey K, eds. Dynamics of mercury pollution on regional and global scales: atmospheric processes and human exposure around the world. Norwell, MA: Springer Publishers, 2005

8 Roels H, Abdeladim S, Ceulemans E, et al. Relationships between the concentrations of mercury in air and in blood and urine in workers exposed to mercury vapour. Ann Occup Hyg 1987:31:135-45.

9 Echeverria D, Aposhian HV, Woods JS, et al. Neurobehavioral effects from exposure to dental amalgam $\mathrm{Hg}^{0}$ : new distinctions between recent exposure and $\mathrm{Hg}$ body burden. FASEB $J$ 1998;12:971-80.

10 Ritchie KA, Gilmour WH, Macdonald EB, et al. Health and neuropsychological functioning of dentists exposed to mercury. Occup Environ Med 2002;59:287-93.

11 Kingman A, Albertini T, Brown U. Mercury concentrations in urine and whole blood associated with amalgam exposure in a U.S. military population. J Dent Res 1998:77:461-71.

12 Åkesson I, Schütz A, Attewell R, et al. Mercury and selenium status in dental personnel-impact of amalgam work and own fillings. Arch Environ Health 1991;46:102-9

13 Ellingsen DG, Efskind J, Berg KJ et al. Renal and immunologic markers for chloralkali workers with low exposure to mercury vapor. Scand J Work Environ Health 2000;26:427-35.

14 Echeverria D. Mercury and dentists. Occup Environ Med 2002:59:285-6.

15 Barregård L, Sällsten G, Järvholm B. People with high mercury uptake from their own dental amalgam fillings. Occup Environ Med 1995:52:124-8.

16 Sällsten G, Thorén J, Barregård L, et al. Long term use of nicotine chewing gum and mercury exposure from dental amalgam fillings. J Dent Res 1996;75:594-8

17 Carta P, Flore C, Alinovi R, et al. Sub-clinical neurobehavioral abnormalities associated with low level of mercury exposure through fish consumption. Neurotoxicology 2003;24:617-23. 